\title{
Mean Change in Intra-Ocular Pressure in Patients Undergoing Trabeculectomy with Mitomycin C
}

\author{
MUNIB UR REHMAN ${ }^{1}$, SHAHID MAHMOOD DAYAL ${ }^{2}$, ALI ZAIN UL ABIDIN $^{3}$ \\ ${ }^{1,3}$ AssistantProfessors, ${ }^{2}$ Professor, \\ Department of Ophthalmology, Khawaja Muhammad Safdar Medical College, Allamalqbal Memorial Teaching Hospital, Sialkot \\ Correspondence to: Dr. Munib Ur RehmanE-mail: dr.muniburrehman@gmail.com Cell: 0333-9002500
}

\begin{abstract}
Aim: To examine the outcomes of trabeculectomy followed by mitomycin $\mathrm{C}$ in term of mean change in intra-ocular pressure in patients presented with primary congenital glaucoma.

Study design: Cross-sectional/observational

Place and duration of study: Department of Ophthalmology, Khawaja Muhammad Safdar Medical College, Allama Iqbal Memorial Teaching Hospital, Sialkot from $7^{\text {th }}$ July 2020 to $6^{\text {th }}$ January 2021.

Methods: Fortypatients of both genders with ages up to 5 years presented with primary congenital glaucoma were enrolled in this study. Patients demographics were recorded after taking written consent from parents/guardians. All the patients were receivedtrabeculectomy with $0.4 \mathrm{mg} / \mathrm{ml}$ Mitomycin $\mathrm{C}$ was applied below the flap for 2 to 3 minutes. Intraocular pressure was examined preoperatively and at $12^{\text {th }}$ day after surgery.

Results:Twenty-four (60\%) were males while 16 (40\%) were females. 30 (75\%) patients were ages $\leq 2$ yearsand $10(25 \%)$ patients had ages $>2$ years. A significant difference was observed regarding mean change in intraocular pressure (pre-operatively $30.48 \pm 3.62$ versus post-operatively $16.35 \pm 2.86$ ) with $p$-value $<0.001$.

Conclusion: Trabeculectomy with Mitomycin $\mathrm{C}$ is very effective for reducing intraocular pressure. A significant decrease in intra-ocular pressure was observed post-operatively.

Keywords: Primary congenital glaucoma, Intra-ocular pressure, Trabeculectomy, Mitomycin C
\end{abstract}

\section{INTRODUCTION}

Reducing intraocular pressure (IOP) is the only evidencebased intervention that can delay the onset and progression of glaucoma, which is sight threatening progressive optic neuropathy. ${ }^{1,2}$ A major risk factor for glaucoma is an elevated IOP which is specified as values measured above $21 \mathrm{mmHg}$. Nevertheless, we know that rather than having an absolute high IOP above $21 \mathrm{mmHg}$, many patients suffer from an individual high IOP presenting with normal IOP ranges accompanied by glaucomatous damage and disease progression. Especially IOPfluctuations, defined as the difference between maximal and minimal IOP values measured during a day, are relevant for progression in glaucoma damage. . $^{3,4}$ Daily IOPfluctuations ranging from 3.17 to $5 \mathrm{mmHg}$ are considered to be physiological. ${ }^{5}$ In contrast, glaucoma patients can show larger IOP variations ranging from 4.8 to $11 \mathrm{mmHg}$. According to other studies, IOP-fluctuation was not an independent risk factor of glaucoma or glaucoma progression.6,7 Evaluation of IOP-values and their diurnal and nocturnal fluctuations can be performed in form of diurnal-nocturnal-IOP-profiles (DNP). ${ }^{8}$ Especially nocturnal IOP-measurements, which cannot be provided in an outpatient setting but often show nocturnal IOP-peaks, are of special relevance for the therapy of glaucoma patients 9,10

Trabeculectomy augmented with mitomycin C remains one of the most popular and effective IOP-lowering surgical techniques for open-angle glaucoma. ${ }^{11}$ The present study was conducted to examine the outcomes in term of change in intraocular pressure in patients underwent

Received on 15-01-2021

Accepted on 02-05-2021 trabeculectomy augmented with Mitomycin C for primary congenital glaucoma.

\section{MATERIALS AND METHODS}

This cross-sectional/observational study was conducted at Department of Ophthalmology, Khawaja Muhammad Safdar Medical College, Allama lqbal Memorial Teaching Hospital, Sialkot from $7^{\text {th }}$ July 2020 to $6^{\text {th }}$ January 2021.A total of 40patients of both genders with ages up to 5 years presented with primary congenital glaucoma were enrolled. Patient's detailed demographics including age, sex and side of eye were recorded. Patients with traumatic or complicated cataract, previous ocular repair, previous ocular trauma and retinal detachment were excluded. Diagnosis was confirmed by examination under general anesthesia. Both eyes were examined. All the patients were received trabeculectomy under general anesthesia with $0.4 \mathrm{mg} / \mathrm{ml}$ Mitomycin C was applied below the flap for 2 to 3 minutes. Scleral flap was sutured using 10/0 nylon applied on corners of scleral flap. Conjunctiva was closed with 10/0 nylon suture. Topical combination of steroid and antibiotic medications was started on the first postoperative day for 10 weeks. Follow-up was taken at $12^{\text {th }}$ day after surgery. Preoperatively and postoperatively intraocular pressure was examined by Perkins tonometer to examine the mean change. Data was analyzed by SPSS 24. Chi-square test was done to examine the mean change in intraocular pressure preoperatively and post operatively.

\section{RESULTS}

There were $24(60 \%)$ males while $16(40 \%)$ females. Thirty $(75 \%)$ patients were ages $\leq 2$ years and $10(25 \%)$ patients had ages $>2$ years. Twenty-two (55\%) patients had right 
eye involved and 18(45\%) had left eye (Table 1). Preoperatively mean intra-ocular pressure was $30.48 \pm 3.62$ $\mathrm{mmHg}$. Post-operatively we found a significant difference regarding mean change in intra-ocular pressure $16.35 \pm 2.86$ $\mathrm{mm} \mathrm{Hg}$ with a significant mean decrease of $14.3 \pm 0.76 \mathrm{p}$ value $<0.001$ (Table 2).

In male preoperative IOP was $29.42 \pm 2.54 \mathrm{~mm} \mathrm{Hg}$ and at $12^{\text {th }}$ postoperative day it was $17.25 \pm 2.44 \mathrm{~mm} \mathrm{Hg}$, a significant difference was observed with $p$-value $<0.001$. In females preoperatively mean IOP was $30.86 \pm 3.62$ and postoperatively it was $16.76 \pm 2.35$, a significant difference was observed with p-value $<0.001$ (Table 3).

Table 1: Age, sex and side of eye wise distribution

\begin{tabular}{|l|l|l|}
\hline Variable & No. & $\%$ \\
\hline Gender & 24 & 60.0 \\
\hline Male & 16 & 40.0 \\
\hline Female & \multicolumn{2}{|l|}{} \\
\hline Age (years) & 30 & 75.0 \\
\hline$\leq 2$ & 10 & 25.0 \\
\hline$>2$ & 22 & 55.0 \\
\hline Side & 18 & 45.0 \\
\hline Left & \multicolumn{2}{|l|}{} \\
\hline Right
\end{tabular}

Table 2: Mean change in intra-ocular pressure at $12^{\text {th }}$ day after surgery

\begin{tabular}{|l|l|l|l|}
\hline $\begin{array}{l}\text { Mean } \\
\text { IOP } \\
\mathrm{mmHg}\end{array}$ & Preoperatively & Post-operatively & P-value \\
\cline { 2 - 4 } & $30.48 \pm 3.62$ & $16.35 \pm 2.86$ & $<0.001$ \\
\hline
\end{tabular}

Table 3: Gender-wise stratification regarding mean change in IOP

\begin{tabular}{|l|l|l|l|}
\hline Variable & $\begin{array}{l}\text { Mean IOP } \\
\text { Preoperatively }\end{array}$ & $\begin{array}{l}\text { IOP Post- } \\
\text { operatively }\end{array}$ & $\begin{array}{l}\mathbf{P} \\
\text { value }\end{array}$ \\
\hline Male & $29.42 \pm 2.54$ & $17.25 \pm 2.44$ & $<0.001$ \\
\hline Female & $30.86 \pm 3.62$ & $16.76 \pm 2.35$ & $<0.001$ \\
\hline
\end{tabular}

\section{DISCUSSION}

In present study we found a significant decrease in intraocular pressure after trabeculectomy augmented with Mitomycin $C(P<0.05)$. These results showed similarity to several previous studies in which significant decrease in intraocular pressure were reported and average decrease was $15.04 \mathrm{~mm} \mathrm{Hg} .{ }^{12-14}$ In this study we found that the mean intraocular pressure before surgery was $30.48 \pm 3.62 \mathrm{mmHg}$ and postoperatively it was $16.35 \pm 2.86 \mathrm{~mm} \mathrm{Hg}$ with a significant decrease of $14.5 \mathrm{~mm} \mathrm{Hg}$ and $\mathrm{p}$-value resulted $<0.001$. Rehman et $\mathrm{al}^{15}$ reported that a significant decrease in mean intraocular pressure after trabeculectomy with Mitomycin C, preoperatively $29.81 \pm 4.80$ versus postoperative $17.21 \pm 3.82$ with $p$-value $<0.002$. Another study by Beatty et $\mathrm{al}^{16}$ reported a significant difference regarding intraocular pressure and they resulted mean IOP fell from a preoperative level of $28.4 \pm 6.9$ to a level of $16.63 \pm 8.06 \mathrm{mmHg}$ at the last follow up $(\mathrm{P}<0.0001)$.

In this study according to gender wise stratification of mean change in intraocular pressure we found that female had high IOP before surgery than the male. In male preoperative IOP was $29.42 \pm 2.54 \mathrm{~mm} \mathrm{Hg}$ and at $12^{\text {th }}$ postoperative day it was $17.25 \pm 2.44 \mathrm{~mm} \mathrm{Hg}$, a significant difference was observed $(P<0.001)$. In females preoperatively mean IOP was $30.86 \pm 3.62$ and postoperatively it was $16.76 \pm 2.35$, a significant difference was observed $(\mathrm{P}<0.001)$. However a significant difference was observed regarding decrease in IOP at $12^{\text {th }}$ day after surgery. These results were comparable to many of previous studies. ${ }^{17,18}$

In present study 24 (60\%) were males while 16 (40\%) were females. $30(75 \%)$ patients were ages $\leq 2$ years and $10(25 \%)$ patients had ages $>2$ years. $22(55 \%)$ patients had right eye involved and $18(45 \%)$ had left eye. These results were similar to the study by Rehman et $\mathrm{al}^{15}$ in which male were predominant $63.15 \%$ as compared to females and majority of patients had ages $>1$ years $63.16 \%$. Our study was conducted at pediatric population and it may be resulted the variation regarding age and gender-wise distribution. A study conducted by Sharma et al ${ }^{19}$ reported that the male to female ratio was $0.92: 1$. The maximum number of cases was between the fifth and eighth decade in both sexes. Another study by Esfandiariet $\mathrm{al}^{20}$ reported male patients were high in numbers $54.3 \%$ as compared to females and the mean age was $62.2 \pm 13.5$ years.

\section{CONCLUSION}

Trabeculectomy with Mitomycin C is very effective for reducing intraocular pressure. A significant decrease in intra-ocular pressure was observed post-operatively with a $\mathrm{p}$-value $<0.0001$. So, Trabeculectomy augmented with Mitomycin $\mathrm{C}$ should be performed where need to decrease elevated intra-ocular pressure.

\section{REFERENCES}

1. Heijl A, Leske MC, Bengtsson B, Hyman L, Bengtsson B, Hussein M. Early Manifest Glaucoma Trial Group. Reduction of intraocular pressure and glaucoma progression: results from the Early Manifest Glaucoma Trial. Arch Ophthalmol2002;120:1268-79.

2. Coleman AL, Miglior S. Risk factors for glaucoma onset and progression. Survey Ophthalmol2008;53 Suppl1: S3-10.

3. Caprioli J, Coleman AL. Intraocular pressure fluctuation a risk factor for visual field progression at low intraocular pressures in the advanced glaucoma intervention study. Ophthalmology 2008;115(7):1123-9.

4. Aoyama A,IshidaK,Sawada A, Yamamoto T. Target intraocular pressure for stability of visual field loss progression in normal-tension glaucoma. Jpn J Ophthalmol 2010; 54: 117-23.

5. Awai-Kasaoka N, noue $\mathrm{T}$, Inatani M, Takihara $\mathrm{Y}$, Ogata-Iwao $\mathrm{M}$, Tanihara $\mathrm{H}$. Prognostic factors in trabeculectomy with mitomycin $\mathrm{C}$ having history of previous glaucoma surgery.Jpn J Ophthalmol2013; 57:514-9.

6. Gedde SJ, Herndon LW, Brandt JD, Udenz DL, Feuer WJ, Schiffman JC. Postoperative complications in the Tube Versus Trabeculectomy (TVT) study during five years of follow-up.Am J Ophthalmol2012; 153:804-14.

7. Jayaram H, Strouthidis NG, Kamal DS. Trabeculectomy for normal tension glaucoma: outcomes using the Moorfields Safer Surgery technique.Br J Ophthalmol2016; 100:332-8.

8. Bengtsson B, Leske MC, Hyman L, Heijl A. Fluctuation of intraocular pressure and glaucoma progression in the early manifest glaucomatrial. Ophthalmology 2007;114(2):205-9.

9. Olawoye $\mathrm{OO}$, Ashaye AO, Baiyeroju AM, Teng CC, Liebmann JM, Ritch R. Outcomes of trabeculectomy with 5fluorouracil at a Nigerian Tertiary Hospital. J Ophthalmic Vis Res 2013; 8(2): 126-33.

10. Bashir R, Sanai M, Azeem A, Altaf I, Saleem F, Naz S. Contribution of GLC3A locus to primary congenital glaucoma in Pakistani population. Pak J Med Sci 2014; 30 (6): 1341-5. 
11. Hafez MI. Trabeculectomy with collagen matrix implantation versus trabeculectomy with mitomycin $\mathrm{C}$ application for the treatment of primary congenital glaucoma. J Egypt OphthalmolSoc 2015; 108: 26-31.

12. Cabourne E, Clarke JCK, Schlottmann PG, Evans JR Mitomycin $C$ versus 5-fluorouracil for wound healing in glaucoma surgery. Cochrane Database Syst Rev 2015; 11 : CD006259.

13. Grezda A, Simaku E, Qirjako G. A comparative study between trabeculectomy with mitomycin-C and conventional trabeculectomy. IJSP 2019; 4;212-6.

14. Khandelwal R, Bijlani M, Raje D, Rathi A. Evaluating the efficacy of short duration Mitomycin $\mathrm{C}$ in safe surgery system trabeculectomy combined with cataract surgery.ClinOphthalmol2019;13:849-57.

15. Wali-Ullah, Illyas $\mathrm{O}$, Rehman $\mathrm{M}$, Khan $\mathrm{H}$. Mean change in intra-ocular pressure following trabeculectomy with mitomycin C in congenital glaucoma. PJO 2018; 34(3).
16. Beatty S, Potamitis T, Kheterpal S, et al Trabeculectomy augmented with mitomycin $\mathrm{C}$ application under the scleral flap. BrJOphthalmol1998;82:397-403.

17. Hsu CR, Chen YH, Tai MC, Lu DW. Combined trabeculotomy-trabeculectomy using the modified Safer Surgery System augmented with MMC: its long-term outcomes of glaucoma treatment in Asian children. Graefes Arch ClinExpOphthalmol 2018; 256: 1187-94.

18. Ghate $D$, Wang $X$. Surgical interventions for primary congenital glaucoma. Cochrane Database Syst Rev 2015; 30: 1.

19. Sharma A, Rawat M, Sharma AK. Effect of mitomycin-cassisted suturelesstrabeculectomy on keratometry and axial length. Adv Hum Biol 2017;7:65-70.

20. EsfandiariH, Pakravan M, Yazdani S, Doozandeh A, Yaseri M, Conner IP. Treatment outcomes of mitomycin caugmented trabeculectomy, sub-tenon injection versus soaked sponges, after 3 years of follow-up: a randomized clinical trial.Ophthalmol Glaucoma 2018; 1(1): 66-74. 